\title{
Use of a DVD to provide dietary and lifestyle information to pregnant women who are overweight or obese: a nested randomised trial
}

Malgorzata A Szmeja', Courtney Cramp ${ }^{1}$, Rosalie M Grivell ${ }^{1,2}$, Andrea R Deussen ${ }^{1}$, Lisa N Yelland ${ }^{3,4}$ and Jodie M Dodd ${ }^{1,2^{*}}$

\begin{abstract}
Background: We conducted a nested randomised trial to evaluate the effect of an educational DVD, providing information about healthy food choices and exercise during pregnancy, on diet and physical activity, among pregnant women who were overweight or obese.
\end{abstract}

Methods: We conducted a nested randomised trial within the context of the LIMIT randomised trial. Women were eligible with a singleton pregnancy between 10 and 20 weeks gestation, and body mass index at the time of their first antenatal appointment of $\geq 25 \mathrm{~kg} / \mathrm{m}^{2}$. All women who were randomised to the Lifestyle Advice Group of the LIMIT trial received a series of consultations with both research dieticians and research assistants, in addition to standard written dietary and exercise materials (Standard Materials Group). Women randomised to the DVD Group received the same consultations and written materials, and additionally received an educational DVD (DVD Group). The primary study outcome was the Healthy Eating Index. Other study outcomes included physical activity, and gestational weight gain. Women completed a qualitative evaluation of all the materials provided.

Results: 1,108 women in the LIMIT Lifestyle Advice Group participated in the nested trial, with 543 women randomised to the DVD Group, and 565 women to the Standard Materials Group. Women who received the DVD compared with those who did not, had a higher mean Healthy Eating Index at 36 weeks gestation (73.6 vs 72.3; adjusted mean difference $1.2 ; 95 \% \mathrm{Cl} 0.2$ to $2.3 ; \mathrm{p}=0.02$ ), but not at 28 weeks gestation (73.2 vs 73.5; adjusted mean difference $-0.1 ; 95 \% \mathrm{Cl}-1.1$ to $0.9 ; \mathrm{p}=0.82$ ). There were no statistically significant differences in physical activity or total gestational weight gain. While most women evaluated the materials positively, frequency of utilisation was poor.

Conclusions: Ongoing attention to the delivery of information is required, particularly with the increased use and availability of digital and multi-media interactive technologies.

Trial registration: Australian and New Zealand Clinical Trials Registry ACTRN12607000161426

Keywords: Obesity, Pregnancy, Randomised trial, Evaluation of information provision

\footnotetext{
* Correspondence: jodie.dodd@adelaide.edu.au

${ }^{1}$ The University of Adelaide, Discipline of Obstetrics \& Gynaecology and The Robinson Research Institute, Women s \& Children s Hospital, 72 King William Road, North Adelaide, South Australia 5006, Australia

2Department of Perinatal Medicine, Women s and Children s Hospital, North Adelaide, South Australia, Australia

Full list of author information is available at the end of the article
}

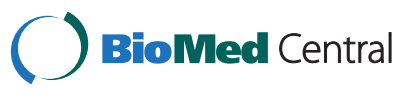

2014 Szmeja et al.; licensee BioMed Central. This is an Open Access article distributed under the terms of the Creative Commons Attribution License (http://creativecommons.org/licenses/by/4.0), which permits unrestricted use, distribution, and reproduction in any medium, provided the original work is properly credited. The Creative Commons Public Domain Dedication waiver (http://creativecommons.org/publicdomain/zero/1.0/) applies to the data made available in this article, unless otherwise stated. 


\section{Background}

Overweight (defined as a body mass index (BMI) between 25.0 and $29.9 \mathrm{~kg} / \mathrm{m}^{2}$ ) and obesity (defined as a BMI greater than or equal to $30.0 \mathrm{~kg} / \mathrm{m}^{2}$ ) [1] are associated with significant health complications for women during pregnancy and childbirth, with a well documented increase in the risk of adverse outcomes, both for women and their infants [2-4]. It is estimated that approximately $35 \%$ of pregnant women in Australia have a BMI above $25 \mathrm{~kg} / \mathrm{m}^{2}$ [3]. More recent population based data would indicate that this is approaching 50\% of pregnant women [5], figures that are consistent with those from the United States [6,7].

While there are an increasing number of reports in the literature outlining the association between high maternal BMI and pregnancy complications, more limited information is available describing the impact of antenatal dietary and lifestyle interventions for women who are overweight or obese. Furthermore, there is increasing recognition that the method of information provision is important in increasing the transfer of knowledge and information retention [8]. This may be of considerable importance in the setting of dietary information presented for weight management. A number of randomised studies have evaluated the use of educational material presented via a DVD or video format to enhance knowledge and treatment compliance, for self management of type 2 diabetes and treatment compliance for parents of children prescribed antibiotics, women choosing mode of birth after prior caesarean birth and for couples undergoing embryo transfer [9-12]. While the clinical care setting of each of these studies varied considerably, and different measures of compliance or success were utilised, the conclusion was that the addition of the DVD or video improved treatment compliance and was an effective method of delivering health care information [9-12]. It is unclear if these findings are applicable to weight management in adult populations, particularly for women during pregnancy.

The aims of the current study, conducted in the context of the LIMIT randomised trial, were two-fold. Firstly, we evaluated in a nested randomised trial, the effect of an educational DVD as a tool to provide information about healthy food choices and exercise during pregnancy on diet and physical activity outcomes. Secondly, we evaluated written materials provided to pregnant women who were overweight or obese, and whether use of these materials improved diet and physical activity outcomes, as part of an antenatal dietary intervention trial.

\section{Methods}

\section{Study design}

We conducted a nested randomised trial in the context of the LIMIT randomised trial, the protocol [13], and the effect of the antenatal lifestyle intervention for women who are overweight or obese on maternal and infant health outcomes having been reported previously [14-17].

\section{Inclusion and exclusion criteria}

Women were eligible for inclusion in the nested randomised trial who had been randomised to the Lifestyle Advice Group of the LIMIT trial [17]. Briefly, women identified with a BMI $\geq 25 \mathrm{~kg} / \mathrm{m}^{2}$ and live singleton pregnancy between $10^{+0}$ and $20^{+0}$ weeks gestation at the time of their first antenatal visit were eligible to participate.

\section{Trial entry}

At the time of a womans first antenatal appointment, her height and weight were obtained and BMI calculated. All women provided written informed consent to participate.

\section{Randomisation, blinding and masking}

Randomisation occurred by telephoning the central randomisation service, which utilised a computer-generated schedule, with balanced variable blocks. During the period of the LIMIT randomised trial, we conducted a nested randomised trial, in which women who were randomised to the Lifestyle Advice group underwent further randomisation to the DVD Group or to the Standard Materials Group.

\section{Treatment schedules \\ DVD Group}

Women who were randomised to the DVD Group received the standard written materials and series of consultations as described subsequently, in addition to the informational DVD. The informational DVD was a specifically prepared educational tool containing information about healthy eating during pregnancy, serving sizes, and exercise during pregnancy. The information content of the DVD was the same as that presented to women in the intervention sessions and written materials.

\section{Standard materials group}

Women randomised to the standard materials group received the standard written materials and series of consultations as described subsequently.

\section{Both treatment groups}

All women who participated in the nested randomised trial and the evaluation of the dietary materials, were randomised to receive the lifestyle intervention, and were provided with dietary advice consistent with current Australian standards [18]. Specifically, women received individualised advice to maintain a balance of carbohydrates, fat and protein, to reduce intake of foods high in refined carbohydrates and saturated fats, while increasing intake of fibre, and promoting consumption of two 
servings of fruit, five servings of vegetables, and three servings of dairy each day [18]. Physical activity advice primarily encouraged women to increase their amount of walking and incidental activity [19].

Within two weeks of randomisation, women attended a planning session with a research dietician, during which a detailed dietary and exercise history was obtained. Women were provided with individualised information, including meal plans, healthy recipes that were quick to prepare, simple food substitutions (including reducing sugar-sweetened soft drinks and fruit juices, reducing added sugar and foods high in refined carbohydrates, and introducing low-fat alternatives), healthy snack and eating out options, and guidelines for healthy food preparation. Women were encouraged to set achievable goals for dietary and exercise change, and were supported to make these lifestyle changes and to self-monitor their progress through the use of a work book provided and ongoing contact with research staff. Women were encouraged to identify potential barriers to them implementing their dietary and physical activity goals. Using these perceived barriers, women were assisted to problem solve, and to develop individualised strategies to facilitate their successful implementation.

All women received this information in both verbal and written formats (comprising the Nutrition in Pregnancy, Exercise in Pregnancy, and Pregnancy Record books), which was reinforced during subsequent inputs provided by the research dietician (at 28 weeks gestation) and trained research assistants (via telephone call at 22, 24, and 32 weeks gestation and a face-face visit at 36 weeks gestation). The Nutrition in Pregnancy book contained written and pictorial information including common pregnancy complications that may be associated with high degrees of gestational weight gain, healthy eating during pregnancy, food groups with specific examples, recommended number of servings per day, portion sizes (including rate your plate), and food label reading. The Exercise in Pregnancy book provided information about the benefits of physical activity during pregnancy, practical tips to increase physical activity, as well as safety information. The Pregnancy Record provided women with a workbook tool in which to record their dietary and exercise goals, and to self-monitor their progress. The Healthy Cooking book provided women with sample weekly menu plans and healthy recipe ideas.

For all women participating in this study, the remainder of their pregnancy care was according to the practices of their caregiver and the local hospital guidelines where they planned to birth.

\section{Study endpoints}

The primary study outcome was the woman s Healthy Eating Index (HEI) during pregnancy, as determined by self-completed food frequency questionnaire.
Women completed the Harvard Semi-quantitative Food Frequency questionnaire (The Willett Questionnaire) at 28 and 36 weeks gestational age. The Willett questionnaire was developed in 1985 in the United States to measure the daily intake of nutrients from 126 food items, with an indication of standard portion size, divided into seven food groups [20], and has been validated for use during pregnancy [21], and in an Australian context [22]. Responses to this questionnaire were considered invalid and hence excluded if more than $25 \%$ of responses were missing, or if total energy intake was unrealistic $(<4500 \mathrm{~kJ}$ or $>20000 \mathrm{~kJ})$ [23]. Using information derived from the food frequency questionnaire, the $2005 \mathrm{HEI}$ was used as an index of diet quality [24], consisting 12 components, with a maximum score of 100. Total fruit (including 100\% juice), whole fruits (excluding juice), total vegetables, dark green and orange vegetables, vegetables and legumes (legumes included as a vegetable only after the Meat and Beans standard was met), total grains and whole grains categories are each scored out of five. Milk (all products made from cows milk, goats milk and soy beverages but excluding products that are primarily fat such as butter, cream, sour cream and cream cheese), meat and beans (meat products, eggs, nuts, seeds, soy-based products and legumes), oils (fats that are liquid at room temperature, from a plant source and not described as hydrogenated or shortening including oils from plant, fish, nuts and seeds or margarines), saturated fat and sodium are each scored out of 10. Calories derived from solid fats (all excess fat from the milk, meat and beans components beyond that would be consumed if only the lowest fat forms were eaten, solid fats added to foods in preparation or at the table including cream, butter, stick margarine, regular or low-fat cream cheese, lard, meat drippings, cocoa and chocolate), alcoholic beverages and added sugars (SoFAAS) are scored out of 20. Scores for saturated fat, sodium and calories derived from solid fats, alcohol and added sugars are reverse scored, where a higher score indicates lower consumption. A HEI above 80 is considered good, between 5080 needs improvement and below 50 is considered poor. The HEI has been validated for use in a pregnant population [25].

Women completed the Short Questionnaire to Assess Health-enhancing physical activity (SQUASH) [26], also at 28 and 36 weeks gestation. The 11-item questionnaire evaluates the time spent in different categories of physical activity, including commuting, leisure, household and incidental, and work related activities. Responses to this questionnaire were considered invalid and hence excluded if the total hours of activity reported per week exceeded the number of hours in a week. Each activity was assigned an estimate of intensity in Metabolic Equivalent Task units (METs) [27]. As the SQUASH questionnaire reports physical activity during an average week, MET-minutes per week (METs/wk) 
were calculated as duration (in minutes) frequency (days per week) MET intensity.

Total gestational weight gain was calculated as the difference between measured weight at 36 weeks gestation and that obtained from the antenatal booking visit. Average weekly gestational weight gain was calculated by dividing total weight gain by the time between measurements in weeks, to account for differences in timing of measurements obtained at trial entry and 36 weeks gestation.

All women were asked to self-complete a questionnaire at four months post-partum, in which they were asked to indicate whether they agreed or disagreed with a series of statements related to the information presented during the course of pregnancy, including whether it was easy to understand, whether they considered it useful, whether the information presented assisted in making healthier food choices, and how often they referred to the materials. Women were also asked to identify whether their knowledge of healthy food choices and exercise during pregnancy had improved. For each question there were five alternate answers ranging from strongly agree to strongly disagree, or when referring to the frequency of use from never to more than once every week .

\section{Sample size}

The primary endpoint was the Healthy Eating Index score at 28 and 36 weeks gestation. Sample size calculations for the LIMIT randomised trial indicated 1090 women were required in the Lifestyle Advice Group [13]. Assuming a mean (SD) Healthy Eating Index score during pregnancy of 72.4 (7.1) [14], and accounting for a response rate of $65 \%$, this sample size provides $90 \%$ power to detect a difference in mean Healthy Eating Index of 2 points between the DVD Group and the Standard Materials Group (80\% power, 2-sided alpha $=$ 0.025 to correct for multiple comparisons due to outcome assessment at 28 and 36 weeks).

\section{Analysis and reporting}

Analyses were performed on an intention to treat basis, according to the treatment group allocated at randomisation. Continuous outcomes were analysed using linear regression models, with treatment effects expressed as differences in means. Binary outcomes were analysed using $\log$ binomial regression models, with treatment effects expressed as relative risks. Both unadjusted and adjusted analyses were performed, with adjustment for the stratification variables centre, parity and BMI, as well as age, socio-economic status and smoking status. For the Healthy Eating Index and total physical activity, a p value of $<0.025$ was required for statistical significance to correct for multiple comparisons due to the two assessment time points at 28 and 36 weeks gestation. For other outcomes measured at a single time point, a $\mathrm{p}$ value $<0.05$ was used to indicate significance and no adjustment was made for multiple comparisons due to the multiple comparisons considered. All analyses were performed based on the available data using SAS v9.3 (Cary, NC, USA).

Responses to the questionnaire assessing women s opinions on the written materials and DVD were assessed descriptively. To determine whether use of the relevant materials was associated with the Healthy Eating Index or total physical activity at 36 weeks gestation, women were classified as users if they indicated they referred to the materials occasionally, sometimes, or often during pregnancy, and non-users if they referred to the materials rarely or never. Mean scores were compared between users and non-users using linear regression models with and without adjustment for centre, parity, BMI, age, socio-economic status, and smoking status.

\section{Ethics}

Ethics approval was granted by the Women s and Children s Local Health Network Human Research and Ethics Committee at the Womens and Childrens Hospital, the Central Northern Adelaide Health Service Ethics of Human Research Committee (Lyell McEwin Hospital) and the Flinders Clinical Research Ethics Committee (Flinders Medical Centre).

\section{Results}

Of the 1108 women randomised the LIMIT Lifestyle Advice Group [17], 543 (49.0\%) were randomised to the DVD Group, and 565 (51\%) to the Standard Materials Group. The flow of participants is outlined in Figure 1, and baseline characteristics of women at the time of trial entry are presented in Table 1. Maternal demographics were similar between the two treatment groups.

\section{Maternal healthy eating index and physical activity}

Valid response rates for the food frequency questionnaire and physical activity questionnaire were similar between treatment groups (Table 2). At 28 weeks gestation there was no evidence of a difference in the Healthy Eating Index of women who did or did not receive the DVD (adjusted mean difference (AMD) -0.12, 95\% confidence interval $(\mathrm{CI})-1.10$ to $0.87, \mathrm{p}=0.82$ ). However, women who received the DVD reported higher mean HEI scores at 36 weeks compared with women who received written materials alone (AMD 1.20, 95\% CI 0.16 to $2.25, \mathrm{p}=0.02$ ). There were no statistically significant differences identified in total physical activity at either 28 or 36 weeks gestation, or total or average gestational weight gain between women who received the DVD, and those who received standard written materials alone (Table 3). 

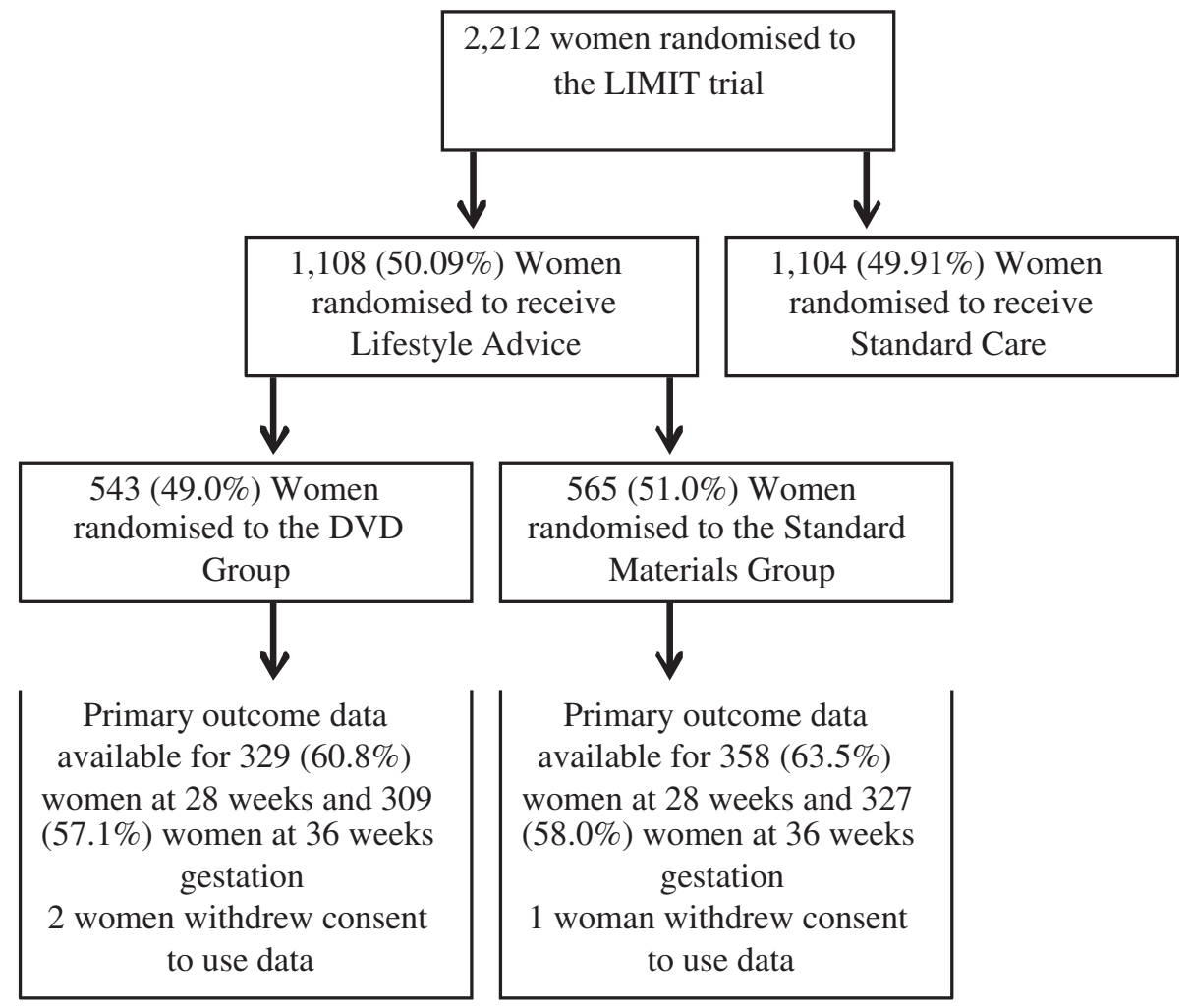

Figure 1 Flow of participants in the nested randomised trial.

\section{Post-partum assessment of maternal self-reported knowledge}

Knowledge questionnaires were returned by 589 women, with a response rate of around $53 \%$ in each group (Table 2). There were no statistically significant differences identified between women in the DVD group and those who received standard written materials in their self-reported knowledge of healthy food choices (DVD Group 201/285 (70.5\%) versus Standard Materials Group 203/301 (67.4\%), adjusted relative risk (ARR) 1.06, 95\% CI 0.95 to $1.18 ; \mathrm{p}=0.30)$, or exercise during pregnancy (DVD Group 224/285 (78.6\%) versus Standard Materials Group 220/301 (73.1\%), ARR 1.05, 95\% CI 0.96 to 1.16; $\mathrm{p}=0.28$ ) (Table 3 ). Similarly, there were no statistically significant differences identified between the two groups in women s sense of improved health (Table 3 ).

\section{Qualitative assessment of the provided study materials}

A total of 568 women provided written feedback in relation to the provided written study materials and response rates were similar between groups (Table 2). While the majority of women both liked the nutrition in pregnancy book (78.3\%), and found the information easy to follow (87.3\%), relatively few women referred to the book sometimes or often during pregnancy $(21.3 \%)$ or in the postpartum period (9.9\%). There was no evidence to suggest that use of the nutrition pregnancy book during pregnancy influenced the Healthy Eating Index (Table 4). Similarly, the majority of women (67.3\%) liked the exercise in pregnancy book, and found the information easy to follow (78.2\%), although few women referred to the book sometimes or often during pregnancy $(15.0 \%)$, or in the postpartum period $(5.5 \%)$. Use of the exercise in pregnancy book was not associated with an improvement in the total physical activity (Table 4).

A total of 152 (28.1\%) women randomised to the DVD Group evaluated the material presented in the DVD, of whom 59 (33.8\%) were overweight and 93 (61.2\%) were obese. Eighty-eight women (57.9\%) agreed or strongly agreed that overall the information presented was easy to understand, as was the information presented about food groups and serving sizes. Seventy-eight women (51.3\%) agreed or strongly agreed that overall the DVD was useful. Eighty-five women (55.9\%) agreed or strongly agreed that they liked the DVD, and 70 women (46.1\%) agreed or strongly agreed that the DVD helped in making healthier food choices. Following the initial viewing of the DVD, $51.3 \%$ of women referred to it at least once again during pregnancy, although only $22.4 \%$ of women used the information contained in the DVD following the birth of their baby, and this was similar for overweight and obese women. DVD use was not associated 


\begin{tabular}{|c|c|c|}
\hline Characteristic & $\begin{array}{l}\text { DVD Group } \\
(N=541)\end{array}$ & $\begin{array}{l}\text { Standard Materials } \\
\text { Group }(N=564)\end{array}$ \\
\hline Maternal Age (Years) ${ }^{*}$ & $29.2(5.6)$ & $29.4(5.3)$ \\
\hline $\begin{array}{l}\text { Gestational Age at } \\
\text { Entry (Weeks) }\end{array}$ & $14.0(11.9-17.3)$ & $14.1(12.0-16.7)$ \\
\hline Body Mass Index $\left(\mathrm{kg} / \mathrm{m}^{2}\right)^{+}$ & $31.0(28.0-35.9)$ & $31.1(28.1-35.8)$ \\
\hline \multicolumn{3}{|l|}{ Body Mass Index Category ${ }^{\#}$} \\
\hline BMI 250-299 & $225(41.6)$ & $233(41.3)$ \\
\hline BMI 300-349 & $156(28.8)$ & $170(30.1)$ \\
\hline BMI 350-399 & $94(17.4)$ & $108(19.1)$ \\
\hline $\mathrm{BMI}>=400$ & $66(12.2)$ & $53(9.4)$ \\
\hline Public Patient ${ }^{\#}$ & $530(98.0)$ & $551(97.7)$ \\
\hline Weight $(\mathrm{kg})^{*}$ & $89.2(18.2)$ & $88.0(16.3)$ \\
\hline Height $(\mathrm{cm})^{*}$ & $165.1(6.7)$ & $164.6(6.5)$ \\
\hline Caucasian ${ }^{\#}$ & $488(90.2)$ & 507 (89.9) \\
\hline Smoker ${ }^{\#}$ & $74(13.7)$ & $80(14.2)$ \\
\hline Nulliparous ${ }^{\#}$ & $224(41.4)$ & $233(41.3)$ \\
\hline \multicolumn{3}{|l|}{$\begin{array}{l}\text { Index of Socio-economic } \\
\text { Disadvantage^} \wedge\end{array}$} \\
\hline Unknown & $1(0.2)$ & $1(0.2)$ \\
\hline $\begin{array}{l}\text { Quintile } 1 \\
\text { (Most Disadvantaged) }\end{array}$ & $183(33.8)$ & $157(27.8)$ \\
\hline Quintile 2 & $128(23.7)$ & $143(25.4)$ \\
\hline Quintile 3 & $68(12.6)$ & 105 (18.6) \\
\hline Quintile 4 & $74(13.7)$ & $76(13.5)$ \\
\hline $\begin{array}{l}\text { Quintile } 5 \\
\text { (Least Disadvantaged) }\end{array}$ & $87(16.1)$ & $82(14.5)$ \\
\hline
\end{tabular}

Includes all women randomised who did not withdraw consent to use their data.

*mean and standard deviation.

${ }^{+}$median and interquartile range.

\#number and \%.

$\wedge$ Socioeconomic index as measured by SEIFA.

Table 2 Response rates by treatment group

\begin{tabular}{lll}
\hline Questionnaire & $\begin{array}{l}\text { DVD Group } \\
(\mathbf{N}=\mathbf{5 4 1})\end{array}$ & $\begin{array}{l}\text { Standard Materials } \\
\text { Group }(\mathbf{N}=\mathbf{5 6 4})\end{array}$ \\
\hline Food Frequency Questionnaire* & & \\
28 weeks & $329(60.8)$ & $358(63.5)$ \\
36 weeks & $309(57.1)$ & $327(58.0)$ \\
Physical Activity Questionnaire* & & \\
28 weeks & $350(64.7)$ & $376(66.7)$ \\
36 weeks & $333(61.6)$ & $359(63.7)$ \\
Knowledge Questionnaire & $287(53.0)$ & $302(53.5)$ \\
Evaluation of Written Materials & $276(51.0)$ & $292(51.8)$ \\
Evaluation of DVD & $152(28.1)$ & N/A \\
\hline
\end{tabular}

Values are number (\%).

*Valid questionnaire responses. with a change in either the Healthy Eating Index or the total physical activity (Table 4).

\section{Discussion}

The results of this nested randomised trial indicate that overweight and obese women reported high rates of knowledge of healthy food choices and exercise during pregnancy. The addition of an educational DVD was associated with modest improvements in maternal diet as measured by the Healthy Eating Index at 36 weeks gestation, but was no more effective in improving physical activity than the information presented in standard consultations and the written study materials. The information presented in the DVD was evaluated by women in a positive manner, the majority either agreeing or strongly agreeing that the information was easy to understand and assisted in making healthier food choices. Similarly, the written materials were viewed positively by participants, although frequency of use was low, and did not correlate with changes in the Healthy Eating Index, physical activity score, or gestational weight gain.

A potential limitation of our study is the reliance on maternal recall with regards to frequency of use, not only of the written study materials, but also of the DVD provided. While this recall may be subject to bias with women responding four months after birth, it would be anticipated that the bias would be operating evenly across both treatment groups, particularly given that the baseline characteristics of participants were comparable at the time of trial entry. Furthermore, we identified no correlation between reported frequency of use of the materials, including the DVD, and changes in reported dietary intake or physical activity, both of which were assessed at two time points during pregnancy. Additionally, there was no correlation between reported frequency of use of the materials and more objective measures of total and average weekly gestational weight gain. A further limitation is the overall low response rate, which may introduce potential non-response bias, with those women who responded potentially more likely to view the materials in a positive fashion. As highlighted previously [17], the majority of women participating in the LIMIT randomised trial were of white Caucasian ethnicity, and our findings may therefore not be generalizable to other pregnant populations.

We have previously reported findings of improved maternal diet quality, including increased consumption of fruits and vegetables and a reduction in the percentage of energy obtained from saturated fats, among overweight and obese pregnant women who received an antenatal dietary and lifestyle intervention [14,17]. Furthermore, women who received the intervention, significantly increased their physical activity, equivalent to 1520 minutes brisk walking on most days of the week [14]. These relatively modest changes in maternal diet and physical 
Table 3 Study outcomes by treatment group

\begin{tabular}{|c|c|c|c|c|c|c|}
\hline Outcome & $\begin{array}{l}\text { DVD Group } \\
(N=541)\end{array}$ & $\begin{array}{l}\text { Standard Materials } \\
\text { Group }(N=564)\end{array}$ & $\begin{array}{l}\text { Unadjusted Treatment } \\
\text { Effect (95\% Cl) }\end{array}$ & $\begin{array}{l}\text { Unadjusted } \\
P \text {-value }\end{array}$ & $\begin{array}{l}\text { Adjusted Treatment } \\
\text { Effect }(95 \% \mathrm{Cl})\end{array}$ & $\begin{array}{l}\text { Adjusted } \\
\text { P-value }\end{array}$ \\
\hline \multicolumn{7}{|l|}{$\begin{array}{l}\text { Healthy Eating Index } \\
\text { Score }\end{array}$} \\
\hline 28 weeks & $73.22(6.79)$ & $73.47(6.45)$ & $-0.26(-1.24,0.73)$ & 0.61 & $-0.12(-1.10,0.87)$ & 0.82 \\
\hline 36 weeks & $73.60(6.58)$ & $72.34(7.00)$ & $1.26(0.20,2.31)$ & 0.02 & $1.20(0.16,2.25)$ & 0.02 \\
\hline \multicolumn{7}{|l|}{ Physical Activity } \\
\hline 28 weeks & $7040.20(3968.84)$ & $6967.30(3943.89)$ & $72.90(-502.19,648.00)$ & 0.80 & $121.48(-453.94,696.90)$ & 0.68 \\
\hline 36 weeks & $5756.54(4062.39)$ & $5865.81(3858.77)$ & $-109.27(-698.64,480.09)$ & 0.72 & $-125.57(-717.73,466.59)$ & 0.68 \\
\hline $\begin{array}{l}\text { Total Gestational Weight } \\
\text { Gain (kg) }\end{array}$ & $9.09(5.75)$ & $9.66(5.73)$ & $-0.58(-1.33,0.18)$ & 0.13 & $-0.58(-1.30,0.13)$ & 0.11 \\
\hline $\begin{array}{l}\text { Average Weekly Gestational } \\
\text { Weight Gain (kg) }\end{array}$ & $0.43(0.29)$ & $0.46(0.28)$ & $-0.02(-0.06,0.01)$ & 0.23 & $-0.02(-0.06,0.01)$ & 0.19 \\
\hline $\begin{array}{l}\text { Increased knowledge of } \\
\text { healthy food choices }\end{array}$ & $201 / 285(70.53 \%)$ & 203/301 (67.44\%) & $1.05(0.94,1.17)$ & 0.42 & $1.06(0.95,1.18)$ & 0.30 \\
\hline $\begin{array}{l}\text { Increased knowledge of } \\
\text { exercise }\end{array}$ & $224 / 285(78.60 \%)$ & 220/301 (73.09\%) & $1.08(0.98,1.18)$ & 0.12 & $1.05(0.96,1.16)$ & 0.28 \\
\hline $\begin{array}{l}\text { Improved health during } \\
\text { pregnancy }\end{array}$ & 229/285 (80.35\%) & $228 / 301(75.75 \%)$ & $1.06(0.88,1.27)$ & 0.53 & $1.05(0.96,1.14)$ & 0.28 \\
\hline
\end{tabular}

Values are mean (SD) and treatment effects are differences in means unless otherwise indicated.

*Values are number (\%) and treatment effects are relative risks.

activity have been associated with a significant $18 \%$ relative risk reduction in the chance of infant birth weight above $4.0 \mathrm{~kg}$ [17] and $4.5 \mathrm{~kg}$ [15].

While provision of the DVD in this nested randomised trial was associated with modest improvement in the Healthy Eating Index at 36 weeks gestation only, there were no differences identified in physical activity score, and the findings could, therefore, represent a chance occurrence. When compared with women of normal BMI, women who are overweight or obese demonstrate poorer diet quality during pregnancy [28], which continues into the early postpartum period [29], consisting specifically of a reduction in dietary intake of grains, vegetables, iron, and folate $[28,30,31]$. While poor diet quality during pregnancy, as measured by the HEI, has been associated with an increased risk of adverse pregnancy outcomes, including glucose intolerance and pre-eclampsia [32], the relative impact of the quite modest differences observed in this nested randomised trial remains uncertain. In non-pregnant adult populations, a decrease in dietary quality using a variety of measures of dietary intake has been associated with increased weight gain over time [33], and increased risk of mortality and morbidity, specifically in relation to cardiovascular disease [34]. While some studies report subtle differences in the Healthy Eating Index and improvements in health and reduced complications of type 2 diabetes [35], other studies report larger differences in diet quality, in association with changes in blood pressure and other measures of cardiometabolic disease, including cholesterol [36,37].

A number of randomised trials in different clinical settings and populations have reported that the provision of audio-visual information in addition to that provided in a standard consultation enhances patient knowledge and understanding [9-12]. King and colleagues [9] evaluated an educational DVD and booklet in addition to the information provided in a standard consultation on the degree of post-prandial glucose control among individuals with

Table 4 Effect of book and DVD use on diet and exercise outcomes at 36 weeks gestation

\begin{tabular}{|c|c|c|c|c|c|c|c|}
\hline Outcome & $\begin{array}{l}\text { Information } \\
\text { Source }\end{array}$ & Users & Non-Users & $\begin{array}{l}\text { Unadjusted } \\
\text { Effect }(95 \% \mathrm{Cl})\end{array}$ & $\begin{array}{l}\text { Unadjusted } \\
\text { P-value }\end{array}$ & $\begin{array}{l}\text { Adjusted Effect } \\
(95 \% \mathrm{Cl})\end{array}$ & $\begin{array}{l}\text { Adjusted } \\
\text { P-value }\end{array}$ \\
\hline $\mathrm{HEl}$ & $\begin{array}{l}\text { Nutrition in } \\
\text { Pregnancy Book }\end{array}$ & $73.76(7.16)$ & $73.21(6.74)$ & $0.55(-0.72,1.82)$ & 0.39 & $0.60(-0.66,1.86)$ & 0.35 \\
\hline $\begin{array}{l}\text { Total Activity } \\
\text { Score }\end{array}$ & $\begin{array}{l}\text { Exercise and } \\
\text { Pregnancy Book }\end{array}$ & $5758.30(3686.65)$ & $5827.75(3858.91)$ & $-69.45(-790.51,651.61)$ & 0.85 & $-2.45(-729.66,724.76)$ & 0.99 \\
\hline $\mathrm{HEI}$ & DVD & $73.76(7.11)$ & $75.60(6.41)$ & $-1.83(-4.93,1.26)$ & 0.25 & $-1.61(-4.59,1.36)$ & 0.29 \\
\hline $\begin{array}{l}\text { Total Activity } \\
\text { Score }\end{array}$ & DVD & 6449.69 (3722.84) & $6224.12(4430.09)$ & $\begin{array}{l}225.57(-1780.00 \\
2231.14)\end{array}$ & 0.83 & $\begin{array}{l}82.66(-1924.09 \\
2089.42)\end{array}$ & 0.94 \\
\hline
\end{tabular}

Values are mean (SD) and effects are differences in means for users of the information source compared with non-users. 
type 2 diabetes. In this study, provision of additional audiovisual information was associated with a significant increase in reported self-monitoring of blood glucose concentrations, a reduction in post-prandial hyperglycaemia, and a lower mean blood glucose concentration, when compared with standard care [9].

Taylor and colleagues [10] evaluated the effectiveness of the addition of audio-visual information to a standard written leaflet in improving parental knowledge and attitudes about the judicious use of antibiotics in children. At assessment six weeks after the intervention, parents who received the audio-visual presentation were more likely to indicate knowledge change and modification of attitudes, favouring the judicious use of antibiotic therapy in their child [10].

There have been several studies that have evaluated the use of an audio-visual tool in clinical scenarios related to obstetrics and gynaecology [11,12]. Farnworth and colleagues [11] developed an audio-visual tool to assist women choosing mode of birth following a prior caesarean section. A total of 32 women were recruited to the study, of whom 16 were allocated to receive the intervention [11]. Although the intervention was associated with a reduction in decisional conflict scores representing uncertainty about their mode of birth, the differences were not statistically significant when compared with routine information provision [11]. While qualitative analysis of the intervention suggested that women experienced an improved ability to reach a decision about their mode of birth, most women who received the intervention did not consider it more useful than the standard information brochure provided by the hospital [11].

The trial conducted by Hope [12] involved 131 couples presenting for infertility treatment, to evaluate the effectiveness of an educational DVD in influencing attitudes and increasing the acceptability of elective single embryo transfer. While women in both groups reported improved knowledge, those who received the DVD were more aware of potential risks and complications associated with a multiple pregnancy [12]. Following the delivery of the intervention, couples who received the DVD were significantly more likely to indicate a preference for elective single embryo transfer when compared with couples who received the standard information brochure (DVD group: 76/92 (82.6\%) versus Standard brochure group: 68/102 (66.7\%), $\mathrm{p}=0.014)$.

The results of these randomised trials, while addressing different research questions, and utilising different methods of evaluation, all indicated that the use of an informational DVD was associated with improved knowledge and compliance. However, there is more limited information available about the role of audiovisual tools in the context of weight management during pregnancy.
We have identified a single study addressing the role of a CD-ROM as a tool to provide information to pregnant and post-partum women with regards to exercise [38]. Fifty women were recruited to the study (25 pregnant and 25 post-partum), and while the study was stated to be randomised, there was significant imbalance in the allocation to treatment groups ( 40 women in the intervention group versus 10 women in the control group) [38], raising concerns about the process of randomisation and integrity of the trial processes. While the study reported that the provision of the intervention CD-ROM was associated with improved exercise knowledge and self-efficacy during pregnancy and the postpartum period [38], the results should be interpreted with caution given the identified methodological flaws.

The evaluation of study materials from the LIMIT randomised trial indicate that the information was presented in a format that women found both easy to follow and useful, although frequency of utilisation was poor. It is recognised that the simple provision of information, either written or visual, is insufficient to initiate behaviour modification resulting in changes in dietary intake or physical activity [8]. Many consider pregnancy to be a teachable moment [39], when women are potentially receptive, and positive towards opportunities to improve not only their own health and wellbeing, but that of their unborn baby [40]. However, many women consider information provided by health professionals with regards to diet and weight gain during pregnancy, to be both contradictory and inadequate $[41,42]$, with the advice a woman receives from family members considered to be more influential [42]. Findings from our group indicate that while pregnant women who are overweight or obese acknowledge the benefits of healthy eating, most report limited self efficacy to initiate behaviour change [43], prompting the need to further evaluate not only the effect of individual psychological characteristics in achieving successful changes [44], but also the way that information and resources are provided to women.

Smart-phone applications and mobile phone technologies are being utilised increasingly, not only as diagnostic tools for clinicians, but also as self-monitoring tools for individual patients [45-48], although the validity of the scientific information presented has been questioned, particularly in relation to those applications used by consumers [49]. Smart-phone applications have been used in adult weight loss settings, often as an adjunct to standard consultations, particularly as a means of facilitating access, increasing participant engagement, and as a tool to overcome potential barriers associated with traditional face-toface health care interactions [50]. A recent systematic review of randomised trials evaluating smart-phone and mobile applications to facilitate a change in health among women [51] identified a number of studies comparing text 
messaging in combination with standard consultations, with standard consultations alone to facilitate weight loss [52-60]. The majority of trials reported an increase in weight loss and improvement in other biochemical measures among individuals who received additional text-messaging support [52-60], with those applications facilitating self-monitoring of progress, goal setting and behavioural feedback among the most highly rated by participants [61].

Smart-phone and mobile technology use is increasing in pregnancy care settings [62], and while more than 1500 applications [63] are available to the public, rigorous evaluation of both content and efficacy has been limited. We are aware of three randomised trials in a pregnancy setting evaluating the use of SMS or text-messaging support to improve pregnancy wellbeing $[64,65]$ and target quit smoking [66]. While this additional support has been reported to improve maternal satisfaction and reduce anxiety during pregnancy $[64,65]$, the role of mobile technology in facilitating change in dietary intake and physical activity patterns, particularly among pregnant women who are overweight or obese, remains to be determined.

\section{Conclusion}

The findings of our nested randomised trial indicate that the provision of an informational DVD was associated with an improvement in dietary quality at 36 weeks gestation, but was not associated with improvements in physical activity or gestational weight gain. While most women evaluated the materials positively, frequency of utilisation was poor. Ongoing attention to the structure, delivery, and robust evaluation of antenatal dietary and lifestyle interventions, including the method of information provision, is required, particularly in an era characterised by increased use and availability of digital and multi-media interactive technologies.

\section{Competing interests}

The authors declare that they have no competing interests.

\section{Authors contributions}

JMD conceived the study design; CC, MS and JMD drafted the manuscript; $J M D, C C, M S, R G, A D, L Y$ all contributed to critical revision of the manuscript drafts and gave final approval for publication. LY and JMD were responsible for the statistical analyses. All authors read and approved the final manuscript.

\footnotetext{
Acknowledgements

We are grateful to the women who participated in this study. This nested randomised trial was conducted within the context of the larger LIMIT randomised trial, supported by the Australian National Health and Medica Research Council (Project Grant, ID 519240). JMD is the recipient of an Australian National Health and Medical Research Council (NHMRC) Practitioner Fellowship (ID 627005). LNY is supported through a NHMRC Early Career Fellowship (ID 1052388). RMG is supported through a NHMRC Early Career Fellowship (ID 1073514). Infrastructure support was provided by The University of Adelaide, and the Women s and Children s Hospital, Flinders Medical Centre, and Lyell McEwin Hospital, Adelaide. The funders had no role in the study design, data collection and analysis, decision to publish, or preparation of the manuscript.
}

\section{Author details}

${ }^{1}$ The University of Adelaide, Discipline of Obstetrics \& Gynaecology and The Robinson Research Institute, Women s \& Children s Hospital, 72 King William Road, North Adelaide, South Australia 5006, Australia. ${ }^{2}$ Department of Perinatal Medicine, Women s and Children s Hospital, North Adelaide, South Australia, Australia. ${ }^{3}$ Women s and Children s Health Research Institute, North Adelaide, South Australia, Australia. ${ }^{4}$ The University of Adelaide, School of Population Health, Adelaide, South Australia, Australia.

Received: 3 September 2014 Accepted: 28 November 2014

Published online: 12 December 2014

\section{References}

1. World Health Organisation: Obesity: Preventing and Managing the Global Epidemic. WHO Technical Report Series Number 894. Geneva: World Health Organisation; 2000

2. Athukorala C, Rumbold AR, Willson KJ, Crowther CA: The risk of adverse pregnancy outcomes in women who are overweight or obese. BMC Pregnancy Childbirth 2010, 10:56.

3. Callaway LK, Prins JB, Chang AM, McIntyre HD: The prevalence and impact of overweight and obesity in an Australian obstetric population. MJA 2006, 184(2):56 59

4. Dodd JM, Grivell RM, Nguyen A-M, Chan A, Robinson JS: Maternal and perinatal health outcomes by body mass index category. ANZJOG 2011, 51(2):136 140

5. Scheil W, Scott J, Catchside B, Sage L, Kennare R: Pregnancy Outcome in South Australia 2011. Adelaide: Pregnancy Outcome Unit, SA Health, Government of South Australia; 2013.

6. Chu SY, Kim SY, Bish CL: Prepregnancy obesity prevalence in the United States, 2004 2005. Maternal Child Health J 2008(July 10 (Epub)).

7. Institute of Medicine: Weight gain during pregnancy: reexamining the guidelines. Edited by Rasmussen KM, Yaktine AL. National Academic Press, Washington D.C.; 2009

8. Shaw K, O Rourke P, Del Mar C, Kenardy J: Psychological interventions for overweight or obesity (Review). Cochrane Database Syst Rev 2005, doi/10.1002/.

9. King $A B$, Wolfe $G S$, Armstrong DU: Evaluation of a patient education booklet (SimpleStart) effect on postprandial glucose control in type 2 diabetes. Diabetes Technol Ther 2007, 9(3):241 245.

10. Taylor JA, Kwan-Gett TS, McMahon EMJ: Effectiveness of an educational intervention in modifying parental attitudes about antibiotic usage in children. Pediatrics 2003, 111(5 Pt 1):e548 e554.

11. Farnworth A, Robson SC, Thomson RG, Watson DB, Murtagh MJ: Decision support for women choosing mode of delivery after a previous caesarean section: a developmental study. Patient Educ Couns 2008, 71(1):116 124

12. Hope N, Rombauts L: Can an educational DVD improve the acceptability of elective single embryo transfer? A randomized controlled study. Fertil Steril 2010, 94(2):489 495.

13. Dodd JM, Turnbull DA, McPhee AJ, Wittert G, Crowther CA, Robinson JS: Limiting weight gain in overweight and obese women during pregnancy to improve health outcomes: the LIMIT randomised controlled trial. BMC Pregnancy Childbirth 2011, 11:79.

14. Dodd JM, Cramp CS, Sui Z, Yelland LN, Deussen AR, Grivell RM, Moran LJ Crowther CA, Turnbull DA, McPhee AJ: Effects of antenatal lifestyle advice for women who are overweight or obese on maternal diet and physical activity: the LIMIT randomised trial. BMC Med 2014, 12:161

15. Dodd JM, McPhee AJ, Turnbull DA, Yelland LN, Deussen AR, Grivell RM, Wittert G, Owens JA, Robinson JS, for the LIMIT randomised trial group: The effect of antenatal lifestyle advice for women who are overweight or obese on neonatal health: the LIMIT randomised trial. BMC Med 2014, $12: 163$.

16. Dodd JM, Newman A, Yelland LN, Turnbull DA, Deussen AR, Grivell RM, Moran LJ, Crowther CA, McPhee AJ, Wittert G, Owens JA, Robinson JS: Effects of antenatal lifestyle advice for women who are overweight or obese on maternal quality of life: the LIMIT randomised trial. 2014

17. Dodd JM, Turnbull DA, McPhee AJ, Deussen AR, Grivell RM, Yelland LN, Crowther CA, Wittert G, Owens JA, Robinson JS: Antenatal lifestyle advice for women who are overweight or obese: the LIMIT randomised trial. BMJ 2014, 348:g1285. 
18. Australian Guide to Healthy Eating [https://www.eatforhealth.gov.au/ guidelines/australian-guide-healthy-eating]

19. Royal College of Obstetricians and Gynaecologists: Recreational Exercise and Pregnancy: Information for you. London: RCOG Press; 2006.

20. Willett WC, Reynolds RD, Cottrell-Hoehner S, Sampson L, Browne ML: Validation of a semi-quantitative food frequency questionnaire: comparison with a 1-year diet record. J Am Diet Assoc 1987, 87(1):43 47.

21. Fawzi WW, Rifas-Shiman SL, Rich-Edwards JW, Willett WC, Gillman MW: Calibration of a semi-quantitative food frequency questionnaire in early pregnancy. Ann Epidemiol 2004, 14:754 762

22. Rumbold AR, Crowther CA, Haslam RR, Dekker GA, Robinson JS: Vitamins C and $\mathrm{E}$ and the risks of preeclampsia and perinatal complications. $N$ Engl J Med 2006, 354(17):1796 1806

23. Meltzer HM, Brantsaeter AL, Ydersbond TA, Alexander J, Haugen M: Methodological challenges when monitoring the diet of pregnant women in a large study: experiences from the Norwegian mother and child cohort study. Matern Child Nutr 2008, 4:14 27.

24. Guenther PM, Reedy J, Krebs-Smith SM: Development of the healthy eating index-2005. J Am Diet Assoc 2008, 108:1896 1901.

25. Pick ME, Edwards M, Moreau D, Ryan EA: Assessment of diet quality in pregnant women using the healthy eating index. J Am Diet Assoc 2005, 105:240 246.

26. Wendel-Vos GC, Schuit AJ, Saris WH, Kromhout D: Reproducibility and relative validity of the short questionnaire to assess health-enhancing physical activity. J Clin Epidemiol 2003, 56:1163 1169.

27. Ainsworth BE, Haskell WL, Herrmann SD, Meckes N, Bassett DRJ, Tudor-Locke C, Greer JL, Vezina J, Whitt-Glover MC, Leon AS: 2011 Compendium of physical activities: a second update of codes and MET values. Med Sci Sports Exerc 2011, 43(8):1575 1581.

28. Tsigga M, Filis V, Hatzopoulou K, Kotzamanidis C, Grammatikopoulou MG Healthy eating index during pregnancy according to pre-gravid and gravid weight status. Public Health Nutr 2011, 14:290 296.

29. Moran LJ, Sui Z, Cramp CS, Dodd JM: A decrease in diet quality occurs during pregnancy in overweight and obese women which is maintained post-partum. Int J Obes 2012, 2012:7. 10.1038/ijo.2012.129 (E-pub)

30. Fazio Ede S, Nomura RM, Dias MC, Zugaib M: Dietary intake of pregnant women and maternal weight gain after nutritional counseling. Rev Bras Ginecol Obstet 2011, 33:87 92.

31. Laraia BA, Bodnar LM, Siega-Riz AM: Pregravid body mass index is negatively associated with diet quality during pregnancy. Public Health Nutr 2007, 10:920 926.

32. Rifas-Shiman SL, Rich-Edwards JW, Kleinman KP, Oken E, Gillman MW: Dietary quality during pregnancy varies by maternal characteristics in project viva: a US cohort. J Am Diet Assoc 2009, 109:1004 1011.

33. Wirt A, Collins CE: Diet quality what is it and does it matter? Public Health Nutr 2009, 12(12):2473 2492.

34. Wolongevicz DM, Zhu L, Pencina MJ, Kimokoti RW, Newby PK, D Agostino $\mathrm{RB}$, Millen BE: Diet quality and obesity in women: the Framingham nutrition studies. Br J Nutr 2010, 103(8):1223 1229.

35. Mangou A, Grammatikopoulou MG, Mirkopoulou D, Sailer N, Kotzamanidis C, Tsigga M: Associations between diet quality, health status and diabetic complications in patients with type 2 diabetes and comorbid obesity. Endocrinol Nutr 2012, 59(2):109 116.

36. Nicklas TA, O Neil CE, Fulgoni VLR: Diet quality is inversely related to cardiovascular risk factors in adults. J Nutr 2012, 142(12):2112 2118.

37. Shah BS, Freeland-Graves JH, Cahill JM, Lu H, Graves GR: Diet quality as measured by the healthy eating index and the association with lipid profile in low-income women in early postpartum. J Am Diet Assoc 2010, 110(2):274 279.

38. Hausenblas HA, Brewer BW, Van Raalte $J$, Cook B, Downs DS, Weis CA, Nigg C, Cruz A: Development and evaluation of a multimedia CD-ROM for exercise during pregnancy and postpartum. Patient Educ Couns 2008, 70(2):215 219.

39. Phelan S: Pregnancy: a teachable moment for weight control and obesity prevention. Am J Obstet Gynecol 2010, 202(2):135. e131-138. Epub 2009 Aug 2015.

40. Kominiarek MA, Vonderheid S, Endres LK: Maternal obesity: do patients understand the risks? J Perinatol 2010, 30(7):452 548.

41. Smith $D$, Lavender $T$ : The maternity experience for women with a body mass index $\geq 30$ kg/m2: a meta-synthesis. BJOG 2011, 118(7):779 789.

42. Tovar A, Chasan-Taber L, Bermudez OI, Hyatt RR, Must A: Knowledge, attitudes, and beliefs regarding weight gain during pregnancy among Hispanic women. Matern Child Health J 2010, 14(6):938 949.
43. Sui Z, Turnbull DA, Dodd JM: Overweight and obese women s perceptions about making healthy change during pregnancy: a mixed method study. Matern Child Health J 2012, 17(1879):1887.

44. Gardner B, Wardle J, Poston L, Croker H: Changing diet and physical activity to reduce gestational weight gain: a meta-analysis. Obes Rev 2011, 12(7):e602 e620.

45. Capozzi D, Lanzola G: Utilizing information technologies for lifelong monitoring in diabetes patients. J Diabetes Sci Technol 2011, 5(1):55 62

46. Godwin ZR, Bockhold JC, Webster L, Falwell S, Bomze L, Tran NK: Development of novel smart device based application for serial wound imaging and management. Burns 2013, 39(7):1395 1402.

47. Milanese S, Gordon S, Buettner P, Flavell C, Ruston S, Coe D, O Sullivan W, McCormack S: Reliability and concurrent validity of knee angle measurement: Smart phone app versus universal goniometer used by experienced and novice clinicians. Man Ther 2014, S1356 689X(14)00111-8. doi: 10.1016/j.math.2014.05.009.

48. Zvornicanin E, Zvornicanin J, Hadziefendic B: The use of smart phones in ophthalmology. Acta Inform Med 2014, 22(3):206 209.

49. Dubey D, Amritphale A, Sawhney A, Amritphale N, Dubey P, Pandey A Smart phone applications as a source of information on stroke. J Stroke 2014, 16(2):86 90.

50. Okorodudu DE, Bosworth HB, Corsino L: Innovative interventions to promote behavioral change in overweight or obese individuals: a review of the literature. Ann Med 2014, 10:1 7 [Epub ahead of print].

51. Derbyshire E, Dancey D: Smartphone medical applications for women s health: what is the evidence-base and feedback? Int J Telemed App/ 2013, 2013:782074.

52. Brindal E, Hendrie G, Freyne J, Coombe M, Berkovsky S, Noakes M: Design and pilot results of a mobile phone weight-loss application for women starting a meal replacement programme. J Telemed Telecare 2013, 19:166 174

53. Carter MC, Burley VJ, Nykjaer C, Cade JE: Adherence to a smartphone application for weight loss compared to website and paper diary: pilot randomized controlled trial. J Med Internet Res 2013, 15(4):e32.

54. Donaldson EL, Fallows S, Morris M: A text message based weight management intervention for overweight adults. J Hum Nutr Diet 2014, 27(Suppl 2):90 97.

55. Haapala I, Barengo NC, Biggs S, Surakka L, Manninen P: Weight loss by mobile phone: a 1-year effectiveness study. Public Health Nutr 2009, 12(12):2382 2391.

56. Napolitano MA, Hayes S, Bennett GG, Ives AK, Foster GD: Using facebook and text messaging to deliver a weight loss program to college students. Obesity (Silver Spring) 2013, 21(1):25 31

57. Norman GJ, Kolodziejczyk JK, Adams MA, Patrick K, Marshall SJ: Fruit and vegetable intake and eating behaviors mediate the effect of a randomized text-message based weight loss program. Prev Med 2013, 56(1):3 7.

58. Park MJ, Kim HS: Evaluation of mobile phone and Internet intervention on waist circumference and blood pressure in post-menopausal women with abdominal obesity. Int J Med Inform 2012, 81(6):388 394.

59. Patrick K, Raab F, Adams MA, Dillon L, Zabinski M, Rock CL, Griswold WG, Norman GJ: A text message-based intervention for weight loss: randomized controlled trial. J Med Internet Res 2009, 11(1):e1.

60. Shapiro JR, Koro T, Doran N, Thompson S, Sallis JF, Calfas K, Patrick K: Text4Diet: a randomized controlled study using text messaging for weight loss behaviors. Prev Med 2012, 55(5):412 417

61. Tang J, Abraham C, Stamp E, Greaves C: How can weight-loss app designers best engage and support users? A qualitative investigation. Br J Health Psychol 2014, Aug 14. doi: 10.1111/bjhp.12114

62. Kaewkungwal J, Singhasivanon P, Khamsiriwatchara A, Sawang S, Meankaew P, Wechsart A: Application of smart phone in Better Border Healthcare Program : a module for mother and child care. BMC Med Inform Decis Mak 2010, 10:69.

63. Tripp N, Hainey K, Liu A, Poulton A, Peek M, Kim J, Nanan R: An emerging model of maternity care: smartphone, midwife, doctor? Women Birth 2014, 27(1):64 67.

64. Evans WD, Wallace $J$, Snider J: Pilot evaluation of the text4baby mobile health program. BMC Public Health 2012, 12:1031. doi:10.1186/1471-2458-12-1031.

65. Jareethum R, Titapant V, Chantra T, Sommai V, Chuenwattana P, Jirawan C: Satisfaction of healthy pregnant women receiving short message service 
via mobile phone for prenatal support: a randomized controlled trial. J Med Assoc Thai 2008, 91(4):458 463.

66. Naughton F, Prevost AT, Gilbert H, Sutton S: Randomized controlled trial evaluation of a tailored leaflet and SMS text message self-help intervention for pregnant smokers (MiQuit). Nicotine Tob Res 2012, 14(5):569 577.

doi:10.1186/s12884-014-0409-8

Cite this article as: Szmeja et al:: Use of a DVD to provide dietary and lifestyle information to pregnant women who are overweight or obese: a nested randomised trial. BMC Pregnancy and Childbirth 2014 14:409.

\section{Submit your next manuscript to BioMed Central and take full advantage of:}

$\otimes$ Convenient online submission

$\otimes$ Thorough peer review

$\bigotimes$ No space constraints or color $\bowtie$ gure charges

$\otimes$ Immediate publication on acceptance

$\triangle$ Inclusion in PubMed, CAS, Scopus and Google Scholar

$\otimes$ Research which is freely available for redistribution 